\title{
25 Research Soure \\ Acute Renal Artery Embolism in SARS-CoV-2 Infection: A Case Report.
}

\section{Huayan Huang}

The First People's Hospital of Fang Cheng Gang City

\section{Chunguang Lin}

The First People's Hospital of Fang Cheng Gang City

\section{Xiuting Wu}

The First Affiliated Hospital of Guangxi Medical University

\section{Siqi Chen}

The First Affiliated Hospital of Guangxi Medical University

\section{Kai Li ( $\square$ doctorlikai@126.com )}

The First Affiliated Hospital of Guangxi Medical University

\section{Case report}

Keywords: 2019 novel coronavirus disease, acute renal artery embolism, hypercoagulability, thrombosis

Posted Date: October 29th, 2020

DOI: https://doi.org/10.21203/rs.3.rs-98090/v1

License: (c) (1) This work is licensed under a Creative Commons Attribution 4.0 International License. Read Full License 


\section{Abstract}

\section{Background}

Coronavirus disease 2019 (COVID-19) is identified as the pneumonia and acute respiratory distress syndrome caused by severe acute respiratory syndrome coronavirus 2 (SARS-CoV2). The intravascular thrombotic phenomena related to the COVID-19 are emerging as an important complication that contribute to significant mortality.

Case presentation

We present a 62-year-old man with severe COVID-19 and type 2 diabetes. After symptomatic and supportive treatment, the respiratory function was gradually improved. However, the patient suddenly developed abdominal pain, and the enhanced CT scan revealed acute left renal artery embolism. Given the risk of surgery and the duration of the disease, clopidogrel and heparin sodium were included in the subsequent treatment. Later, the abdominal pain and hypercoagulable state disappeared, and the effect was still satisfactory.

\section{Conclusions}

This report clarifies the challenges posed by embolism complications in the management of COVID-19 patients. Thrombosis is at a high risk in patients with severe COVID-19 pneumonia because of hypercoagulable state, blood stasis and endothelial injury. Thrombotic events caused by hypercoagulation status secondary to vascular endothelial injury deserves our attention. Because timely anticoagulation can reduce the risk of early complications, as illustrated in this case report.

\section{Background}

COVID-19 has been declared as a pandemic by World Health Organization in March, 2020. Recent studies show that severe COVID-19 pneumonia is associated with a coagulopathic state and may increase the risk of thrombotic complications [1]. The current common thrombotic complications mainly include venous thrombosis events, pulmonary thrombosis, and myocardial infarction. However, we have noted that reports of embolization events that occur in renal arteries are rare. We present a case of acute renal artery embolism in a SARS-CoV-2-positive patient.

\section{Case Presentation}

A 62-year-old man with a history of type 2 diabetes presented with fever that started five days ago. Cough, fatigue, or abdominal pain were not present. At admission, the body temperature was $36.7{ }^{\circ} \mathrm{C}$, and the patient was diagnosed with SARS-CoV-2 infection by reverse transcriptase-polymerase chain reaction (RT-PCR) assay. Vital signs on presentation revealed heart rate of 76 beats/minute, respiratory rate of 20 breaths/minute, and blood pressure of $117 / 65 \mathrm{mmHg}$. A chest computed tomography scan showed 
ground glass-like shadows multiple consolidations in the both upper lobes (Fig. 1). Initial peripheral blood samples revealed that there was no hypercoagulability (Table 1).

Table 1

Laboratory values on admission and the period of the onset of abdominal pain.

\begin{tabular}{|llll|}
\hline & Admission & $\begin{array}{l}\text { Period of } \\
\text { abdominal pain }\end{array}$ & Reference range \\
\hline WBC $\left(\times 10^{9} / \mathrm{L}\right)$ & 3.80 & 30.10 & $(4.00-10.00)$ \\
\hline Neutrophil $\left(\times 10^{9} / \mathrm{L}\right)$ & 2.26 & 27.38 & - \\
\hline Lymphocyte $\left(\times 10^{9} / \mathrm{L}\right)$ & 0.96 & 0.86 & - \\
\hline Platelets $\left(\times 10^{9} / \mathrm{L}\right)$ & 161 & 130 & $150-350$ \\
\hline C-reactive protein $(\mathrm{mg} / \mathrm{dL})$ & - & 140.70 & $\leq 0.5$ \\
\hline Activated partial & 33.4 & 26.4 & $25.1-35.0$ \\
\hline thromboplastin time $(\mathrm{s})$ & & & $0-243$ \\
\hline D-dimer $(\mathrm{ng} / \mathrm{ml})$ & 177 & 1008 & $0.80-1.20$ \\
\hline International normalized ratio & 1.13 & 1.00 & $2-4$ \\
\hline Fibrinogen $(\mathrm{g} / \mathrm{L})$ & 3.79 & 3.24 & $1-5$ \\
\hline Fibrinogen degradation & 1.09 & 6.14 & $0-15$ \\
\hline products $(\mu \mathrm{g} / \mathrm{mL})$ & & & $90.3 \pm 13.2$ \\
\hline Erythrocyte sedimentation & 28 & - & \\
\hline rate $(\mathrm{mm} / \mathrm{h})$ & & 98.60 & \\
\hline Antithrombin $\otimes(\%)$ & 81.80 & & \\
\hline
\end{tabular}

According to the fifth edition of Chinese New Coronavirus (2019-nCoV) Infection Treatment Plan Guide [2], the coronavirus pneumonia diagnosed was classified as mild type. After admission, he was given routine antiviral and glycemic management of diabetes. Traditional Chinese medicine was used as supportive treatments. Three days later, the patient developed shortness of breath and the symptom gradually worsened. The blood gas analysis showed an oxygenation index result of 172 . Subsequently, the treatment regimen was switched to methylprednisolone $80 \mathrm{mg}$ per day and ceftriaxone in accordance with guidelines for severe cases. After symptomatic and supportive treatments, the patient's respiratory function improved and he was diagnosed with mild COVID-19. On day 12 of hospitalization, the patient reported sudden-onset severe pain in the left waist. The Peripheral blood examination at that time suggested significantly elevated d-dimer level of $1008 \mathrm{ng} / \mathrm{ml}$ (Table 1). Abdominal and urinary color 
doppler ultrasound showed no abnormalities. Two days later, the enhanced CT scan revealed the left renal artery embolism and threatening ischemia (Fig. 2). Given the risk of surgery and the duration of the disease, the patient underwent clopidogrel $300 \mathrm{mg}$ per day and heparin sodium $0.4 \mathrm{ml}$ every 12 hours. After that, the dosage was adjusted according to the change of laboratory parameters. On blood examination one week later the level of D-dimer was normal, and the pain in the left waist had completely resolved.

\section{Discussion And Conclusions}

In this case, acute renal artery embolism suddenly occurred during the treatment of COVID-19 and subsequently led to left renal threatening ischemia. The laboratory test indicating thrombotic complications was elevated D-dimer. Previous studies have shown that elevated D-dimer was a risk factor for death in patients with SARS-CoV-2 infection, especially in elderly patients [3, 4]. The hypercoagulation status of COVID-19 and the subsequent series of vascular complications are a vital topic that is currently emerging [5]. The question of anticoagulant therapy at prophylaxis dose or even higher was subsequently raised [6]. It has been suggested that immune-mediated reaction or direct viral infection of the endothelium will lead to recruitment of immune cells, which may develop into extensive endothelial dysfunction [7]. Angiotensin converting enzyme 2 (ACE2) receptors are expressed in organs including lung, heart, kidney and intestine. Vascular endothelial cells also express angiotensin converting enzyme 2 receptor. And the virus can directly infect endothelial cells by converting enzyme 2 and cause diffuse endothelial inflammation [8]. SARS-CoV-2 infection can develop into acute respiratory distress syndrome. Similar to other viral infections, early cytokine storms are caused by overproduction of response proinflammatory cytokines including tumor necrosis factor, interleukin- 6 and interleukin- $1 \beta$, resulting in an increased risk of multiorgan failure and vascular hyperpermeability [9]. The main function of thrombin in the immune response is to promote the formation of clots by activating platelets and converting fibrinogen to fibrin. However, it is worth noting that the cellular effect of thrombin, mainly par-1 (proteinase-activated receptors), can further enhance inflammation [10]. Protein C system, tissue factor pathway inhibitor and antithrombin are defective during inflammation, which impairs the coagulantanticoagulant balance and leads to the formation of microthrombus [11]. The hypercoagulation status of blood caused by the infection of SARS-CoV-2 can lead to a variety of intravascular thrombotic phenomena, ranging from limited venous and arterial thrombosis to fatal disseminated intravascular coagulation.

Thrombotic events caused by hypercoagulation status secondary to vascular endothelial injury deserves our attention. Because timely anticoagulation can reduce the risk of early complications.

\section{Abbreviations}

COVID-19 Coronavirus disease 2019

SARS-CoV2 severe acute respiratory syndrome coronavirus 2 


\section{Declarations}

Acknowledgements

We want to express our gratitude to The First People's Hospital of Fang Cheng Gang City for help and support.

\section{Declarations}

The research was conducted in accordance with the ethical standards of all applicable national and institutional committees and the World Medical Association's Helsinki Declaration.

\section{Authors' contributions}

Huayan Huang, Chunguang Lin and Chunguang Lin contributed in the analysis and interpretation of data; Huayan Huang and Xiuting Wu drafted the work and Kai Li revised it. The author(s) read and approved the final manuscript.

\section{Funding}

This report was supported by The First People's Hospital of Fang Cheng Gang City and the First Affiliated Hospital of Guangxi Medical University.

\section{Availability of data and materials}

Not applicable.

\section{Ethics approval and consent to participate}

Ethical approval was obtained from The First People's Hospital of Fang Cheng Gang City and the First Affiliated Hospital of Guangxi Medical University. Written consent was obtained from the patient.

\section{Consent for publication}

Was obtained from the patient and from The First People's Hospital of Fang Cheng Gang City.

\section{Competing interests}

The authors in this study have no conflict of interest.

\section{Footnotes}

Not applicable.

\section{References}


1. Klok FA, Kruip MJHA, van der Meer NJM, Arbous MS, Gommers DAMPJ, Kant KM, et al. Incidence of thrombotic complications in critically ill ICU patients with COVID-19. Thromb Res. 2020; 07:191. doi: 10.1016/j.thromres.2020.04.013

2. Lin L, Li TS. Interpretation of "guidelines for the diagnosis and treatment of novel coronavirus (2019ncov) infection by the national health commission (trial version 5)". Zhonghua yi xue za zhi. 2020; 100: E001.

3. Zhou F, Yu T, Du R, Fan G, Liu Y, Liu Z, et al. Clinical course and risk factors for mortality of adult inpatients with COVID-19 in Wuhan, China: a retrospective cohort study. Lancet. 2020; 395(10229):1054-1062.

4. Arachchillage DRJ, Laffan M. Abnormal coagulation parameters are associated with poor prognosis in patients with novel coronavirus pneumonia. Journal of thrombosis, haemostasis: JTH. 2020; 18(5):1233-1234.

5. Thachil J, Tang N, Gando S, Falanga A, Cattaneo M, Levi M, et al. ISTH interim guidance on recognition and management of coagulopathy in COVID-19. J. Thromb. Haemost. 2020; 18(5):10231026.

6. Tang N, Bai H, Chen X, Gong J, Li D, Sun Z, et al. Anticoagulant treatment is associated with decreased mortality in severe coronavirus disease 2019 patients with coagulopathy. Journal of thrombosis. 2020; 18(5):1094-1099.

7. Varga Z, Flammer AJ, Steiger P, Haberecker M, Andermatt R, Zinkernagel AS, et al. Endothelial cell infection and endotheliitis in COVID-19. 2020; 395(10234):1417-1418.

8. Ferrario CM, Jessup J, Chappell MC, Averill DB, Brosnihan KB, Tallant EA, et al. Effect of angiotensinconverting enzyme inhibition and angiotensin II receptor blockers on cardiac angiotensin-converting enzyme 2. Circulation. 2005; 111(20):2605-2610.

9. Meduri GU, Kohler G, Headley S, Tolley E, Stentz F, Postlethwaite. Inflammatory cytokines in the BAL of patients with ARDS. Persistent elevation over time predicts poor outcome. Chest. 1995; 108(5):1303-1314.

10. José RJ, Williams AE, Chambers RC. Proteinase-activated receptors in fibroproliferative lung disease. Thorax. 2014; 69(2):190-192.

11. Jose RJ, Manuel A, Respiratory medicine. COVID-19 cytokine storm: the interplay between inflammation and coagulation. The Lancet. 2020; 10.1016/s2213-2600(20)30216-2.

\section{Figures}



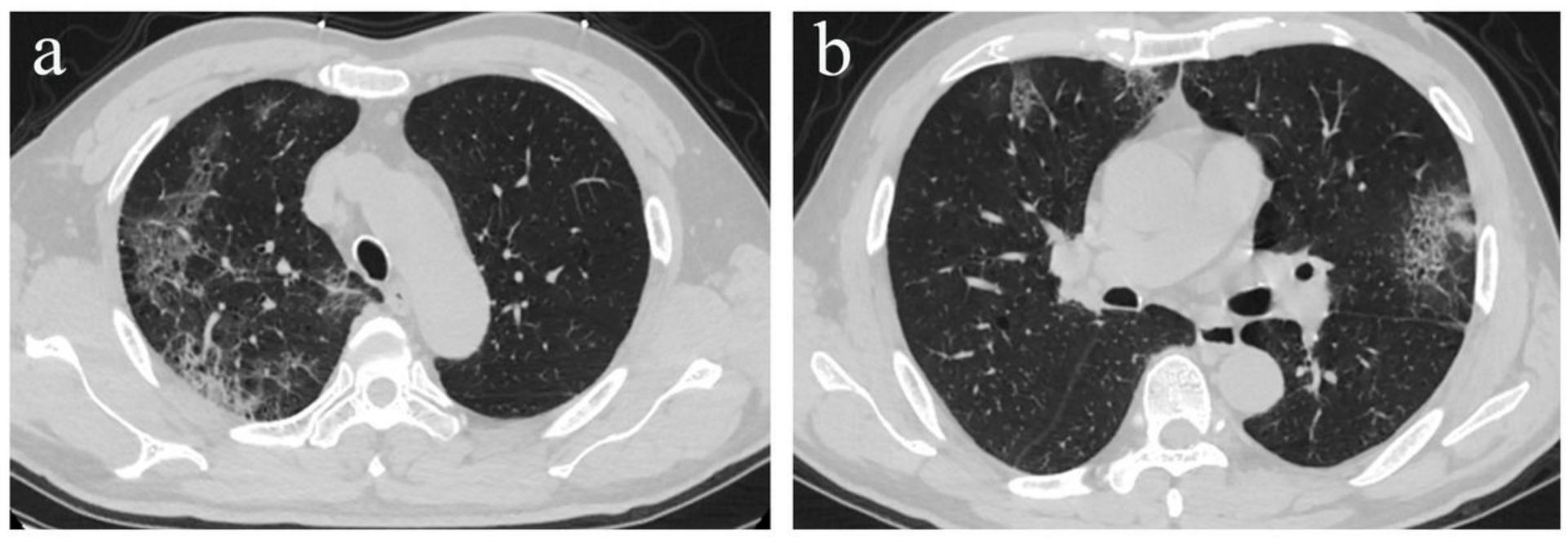

Figure 1

Chest CT shows ground glass-like shadows and multiple consolidations in the both upper lobes.
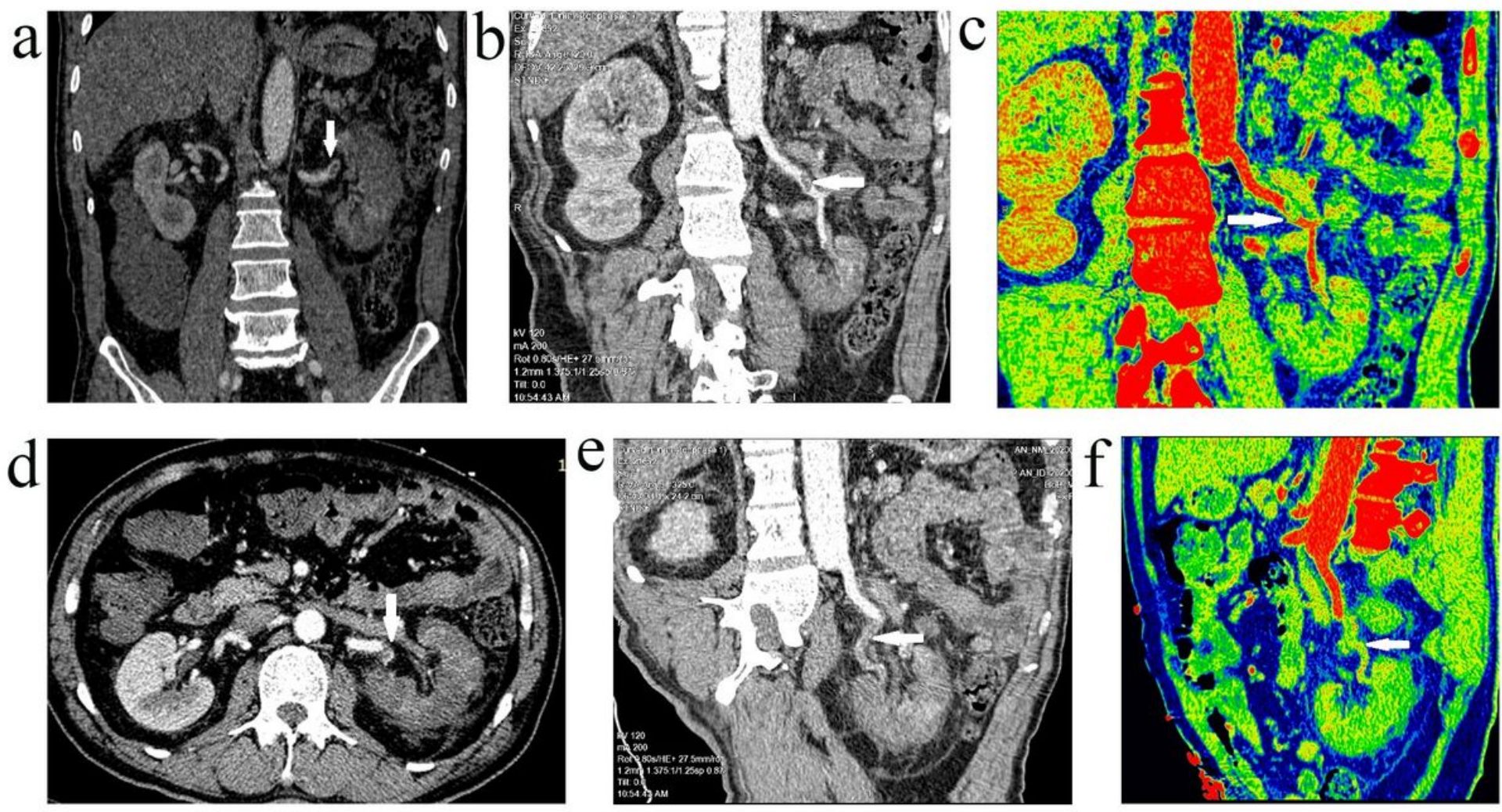

Figure 2

Contrast-enhanced CT indicates the filling defect of the main trunk (a, b, c, white arrow) and its posterior branches ( $d, e, f$, white arrow) of the left renal artery. 